\title{
MASSIVE, PARTIALLY ONLINE CS1 COURSE
}

\author{
Tamar Vilner, Ela Zur, The Open University of Israel, Israel
}

\section{Abstract}

The Open University of Israel (OUI) has an open admissions policy and is based primarily on distance learning. As in other universities, our CS1 course includes the topics recommended in the Computer Science Curricula (2013). The large number of students who register for the course (from 700-900 students per semester) presents us with unique challenges in management. In this paper, we describe the efforts we have devoted to making the learning and teaching process as uniform as possible for all students taking the course. We describe the research we conducted in order to ascertain whether there is a correlation between regular or intensive tutoring groups and student success in CS1 and whether the specific tutors affect student success. We were satisfied that the teaching of our course is quite uniform.

\section{Background}

\section{The Open University of Israel}

The OUI features an open admissions policy and study programs based primarily on distance learning. The university offers a variety of undergraduate and graduate degree programs (see the OUI website), which rely almost entirely on independent study. Courses are taught through course books developed at the OUI which also benefit students at other universities, and videotaped lectures designed specifically for OUI students. OUI courses feature optional face-to-face small group tutorials and a predefined assignment submission schedule. In order to receive credit, students must successfully pass a final exam. The OUI also makes use of advanced web-based technologies (Gal-Ezer, Vilner, \& Zur, 2009) in order to facilitate its distance-learning methodology.

\section{The CS1 Course}

\section{Course Material and Assignments}

The CS1 course, Introduction to Computer Science Using Java, is based on the textbook "Java Software Solutions", by Lewis and Loftus (2012). Dr. Amir Goren and Tamar Vilner, of the OUI mathematics and computer science department, present a series of lectures which are available on the course website, and which contain all material covered in the course. As in introductory courses at other universities, our course includes the topics recommended in the Computer Science Curricula (2013). We teach Java using the BlueJ environment (BlueJ Website). 
Along with the course material, we include eight assignments, of which students are required to submit at least five, according to the deadlines. The assignments are graded, and calculated into the final grade of the course. Each assignment includes questions that relate to various theoretical subjects, and that require writing Java programs.

\section{Face-to-Face Meetings}

CS1, like all OUI courses, incorporates face-to-face meetings held at OUI study centres throughout the country. The tutorials are offered in regular mode - two-hour meetings held every other week, and intensive mode - three-hour weekly meetings. Registration for the course is based on signing up for one of the two tutorials. Although attendance is not mandatory, it is highly recommended. The intensive mode costs more than the regular one. To assist students who live far from a study centre, or those who cannot attend face-to-face meetings, a "Zoom" group allows an instructor to teach a live class remotely from a studio on the OUI campus.

\section{Course Website}

The course website, which serves as an interactive learning environment, provides two types of communication channels - an administrative channel and an academic channel that includes a message board, discussion forums and enrichment materials. These include supplementary study materials, exercises, and exams for self-assessment, demonstrations, feedback on assignments, links to the recorded lectures and videotaped tutorial sessions, and links to relevant websites. The website also contains sample exams from previous semesters.

\section{Managing a Massive Open Online Course}

In recent years, many universities have begun to offer Massive Open Online Courses (MOOCs), which have become a popular topic in academic discussions. Although our CS1 course in not considered a MOOC, the issues we deal with are similar, and thus, we have checked the literature regarding managing a course with numerous students, especially with regard to grading assignments and exams.

MOOCs offer internet-based university-style courses for large numbers of learners. Staubitz et al. (2016) takes a closer look at peer assessments as a tool for delivering individualized feedback and assignments to MOOC participants. The paper describes a peer assessment workflow and its implementation on the openHP1 and open SAP MOOC platform.

Vihavainen, Paksula, and Luukkainen define an Extreme Apprenticeship model that is based on a set of values and practices that emphasize learning by doing together, with continuous feedback, as the most efficient means for learning (2011). They demonstrate how the method has been applied to a CS1 programming course. Vihavainen, Luukkainen, and Kurhila (2013) used this method in their MOOC introductory programming course, thus ensuring that students proceeded step-by-step in the desired direction. The feedback was provided by human advisors (teachers), however, they don't describe how they maintain uniformity when checking assignments. 
Stephenson (2018) reports on a recent experience using exams that include two portions: one, a closed book multiple choice test answered on paper, and the other, a computerized programming portion where students were asked to create small programs using their usual development tools and reference materials. They tried this version instead of exams that asked students to write small programs on paper, after the students expressed the opinion that exams on paper were not reflective of the "real world", and thus their grades on such exams would not accurately reflect their programming ability. They found that both the students and the course instructors preferred the exams that included computerized programming questions.

The use of automatic assessment has been less extensive, mainly because almost all existing systems are based on output comparison. If the output is the expected, the code is correct. Otherwise, it is reported as wrong, even if there is only one typo in the code. Insa and Silva (2015) introduce a new code assessment method that also verifies properties of the code, thus marking the code even if it is only partially correct.

$\mathrm{Ju}$ et al. (2018) describe a system that "enables realistic in-class coding-based exams with broad Internet access". They report on "lessons and experience creating and administering such exam, including autograding-related pitfalls for high-stakes exams”".

\section{Managing our CS1 Massive Course}

Each semester, about 700-900 OUI students enrol in the CS1 course, which is mandatory for all undergraduate computer science programs. The students are located all over the country, and attend face-to-face study groups led by about twenty tutors. Great effort is made by the course coordinator to ensure that the teaching is as consistent as possible for all the students in all the groups.

First, a tutors meeting is held immediately preceding each semester. Tutors discuss issues regarding teaching. Each course has its own timetable (scheduling, dates for submitting assignments, etc.), so tutors attempt to teach more or less the same materials. The course coordinator provides the slideshows for each face-to-face meeting and tutors try to present similar examples and to give the students the same problems to solve.

As mentioned above, before the start of each semester, students receive the assignments which they will need to submit, along with a list of deadlines. Naturally, all students receive the identical exercise booklet, and the course coordinator tries to make assignment grading as consistent as possible. For that purpose, tutors are divided into eight teams of two or three for the purpose of preparing one assignment each. This includes preparing a solution for that exercise, a tester for checking the code of the exercise, and a guide of typical errors and number of points to subtract from the grade when such errors occur. This creates an optimal environment for grading the exercises consistently in all groups by all the tutors. Since each assignment in the course web has a discussion group, in which students may ask questions, the team responsible for a particular assignment is expected to answer the students' questions in this forum. This helps the students receive uniform answers to their questions, and other 
tutors need not enter the forums to answer the many questions. Each tutor is responsible for one assignment only, and shares information for the other assignments with his or her colleagues.

\section{Student Support}

Tutors are also expected to provide student support during the learning process. Each tutor has a specific hour during the week which is dedicated to answering student questions by phone. As there are about twenty tutors, and a student is not required to call his or her own tutor, assistance is available to students for about 15 hours per week (there is some overlap of tutor hours, of course.) Email and discussion groups on the course website are the most popular channels used by students to contact tutors and other students. We know, of course, that the students also have closed groups on Facebook and WhatsApp, but we do not interfere, although we know that many of the exercise solutions are published there.

\section{Final Exams}

As already mentioned, in order to complete a course, students must submit assignments throughout the semester and pass the final exam. Exams are held at OUI study centres throughout the country, and in embassies worldwide for those studying abroad. At the end of the exam, they are collected and sent back to OUI headquarters, where they are distributed to the course coordinators for grading. In order to ensure that the exams are graded fairly, all exams are graded by the course coordinator, usually with help of one or two tutors. Each grader checks the same questions across the board. In this way, different grading styles balance each other out, ensuring uniformity.

As one can see, we expend much effort in order to create a consistent and uniform learning and teaching process. We decided to evaluate whether these efforts are beneficial. In the following sections we will describe our research.

\section{Research Methodology}

\section{Research Questions}

- Is there a correlation between student success in CS1 and participation in regular or intensive tutoring?

- To what extent is there a connection between specific group tutors and student success in CS1?

\section{Research Population and Research Tools}

The study included 12,242 students enrolled in our CS1 course during the years 2010-2018. The data is taken from the university's enrolment and grade database. 


\section{Results}

\section{Background Details of Students}

Figure 1 shows the number of students enrolled in the CS1 course over the years. As is evident, the numbers have been increasing since 2011.

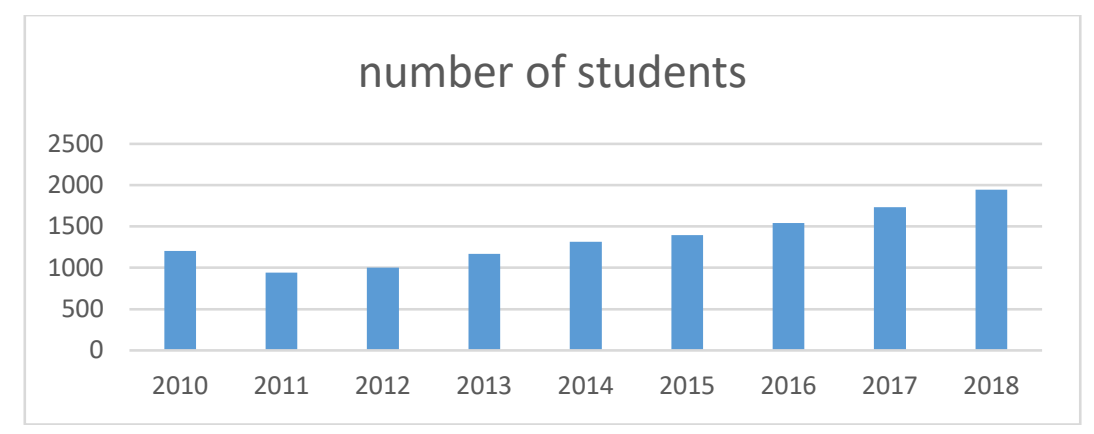

Figure 1. Number of students enrolled in CS1 since 2010

We collected some background details about the students:

- As can be seen worldwide, most of the student population is male, while females are in the minority. We found that the percentage of female computer science students has been hovering at around 20\%, having dropped to 19\% in 2013-2014 and having increased to $21 \%$ in 2018 (Vilner \& Zur, 2006; Barr, 2018).

- There has been an increase in students completing their high school matriculation exams. So, although the OUI has an open admission policy, even for applicants who haven't complete high school, we found that the majority of the students attended high school. And while only $62 \%$ declared that they had a matriculation certificate in 2010 , by $2018,77 \%$ of OUI students were high school graduates.

- The average age of students enrolled in the CS1 course over the years has remained between 26 and 27 .

- Since CS1 is the first course in the undergraduate computer science program, and must be passed in order to continue with the program, we found that about $10-11 \%$ of the students repeated this course.

- The majority of students chose to register for intensive tutoring. However, this percentage is dropping. While $81 \%$ of students studied in intensive groups in 2010 , only $67 \%$ chose to do so in 2018. An explanation for this might lie in the development of technologies that we use in our tutoring sessions, such as the Zoom group.

\section{Student Advancement over the Course of a Semester}

The course does not require any previous programming knowledge, and even students with no background at all can achieve a high level of success. Since we have an open admission policy, and this is usually the first course students take towards an undergraduate degree program in CS, the students are very heterogeneous in their level of knowledge and skills when beginning the course. Some students have studied CS in high school, some are already programmers in the high tech industry, and some have no knowledge at all. As a result, the dropout rate is quite high. Figure 2 shows student advancement over the semester. One can 
see that while $93 \%$ of the students enrolled in the course submit at least one assignment during the semester, only $71 \%$ complete all the exercise requirements. Only $64 \%$ of the students attended the final exam, and just $42 \%$ succeeded in the course.

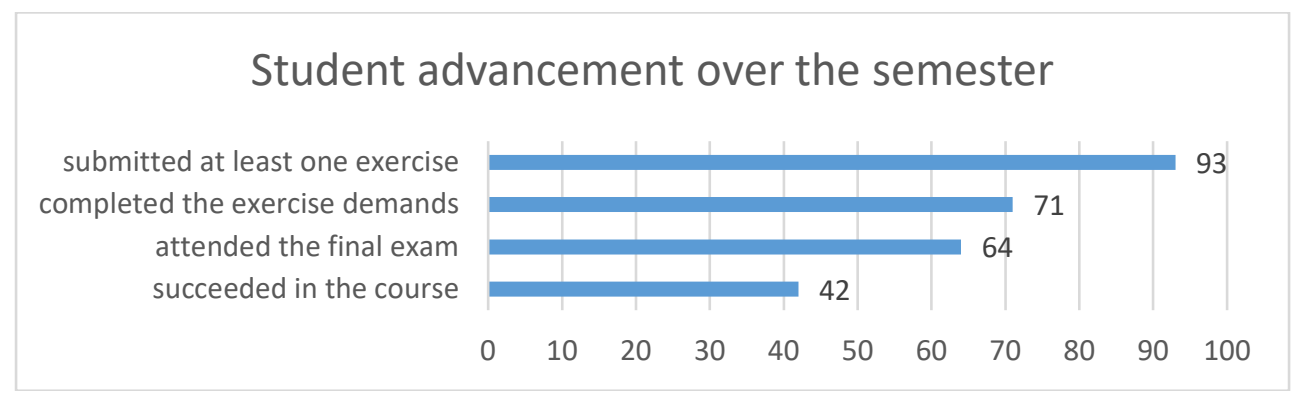

Figure 2. Student advancement over the semester

\section{Intensive Tutoring Versus Regular Tutoring}

For our research, we conducted an evaluation of all students in every study centre, but for this paper, we focused on students at our Tel-Aviv site. Table 1 shows how many students enrolled in this large central-Israel study centre, which hosts more than ten CS1 study groups per semester; 5-6 in regular-tutoring mode, and the rest in intensive mode. We chose this particular site as the focus of our research, since the large number of groups means that there is at least one group per day, which allows students to choose a group according to their preference for particular days of the week and convenience. The groups are therefore heterogeneous as far as student level, with no one group containing only stronger or weaker students. The exception is the separation between regular and intensive groups. Usually, most of the students who choose the regular groups have a background in programming and prior knowledge, particularly in Java.

Table 1: $\quad$ No. of students who studied in Tel-Aviv centre

\begin{tabular}{lccccccccc}
\hline Year & 2010 & 2011 & 2012 & 2013 & 2014 & 2015 & 2016 & 2017 & 2018 \\
\hline Regular & 177 & 164 & 182 & 283 & 317 & 343 & 471 & 514 & 634 \\
Intensive & 277 & 231 & 278 & 274 & 336 & 347 & 374 & 470 & 437 \\
Total & 454 & 395 & 460 & 557 & 653 & 690 & 845 & 984 & 1071 \\
\hline
\end{tabular}

We found differences in the rate of success between students who participated in the regular and intensive modes, with significant differences between the modes noted in the percentage of students who passed the course, in exam scores, and in the final grades (which take into account assignment scores, and are much higher than the exam scores). We found that the students who chose the regular groups had higher success rates. This can be explained by the fact that most of these students already had programming experience and registered for the regular groups since they did not intend to attend the meetings anyway.

Here are some examples:

- During the first semester of $2010,54.4 \%$ of the students in the regular group passed the course, as compared to $38.3 \%$ of the students in the intensive group. The average 
exam score was 68.36 versus 55.18, and the average final grade was 83.12 vs 77.82 for the students who chose regular tutoring. All of these results are significant $(p<0.05)$.

- In the first semester of 2013 , the success rate was $58.4 \%$ as compared to $41.5 \% ; 75.92$ vs 64.02 on the exam scores, with no significant differences in the final grades.

- During semester B of 2014, significant differences were noted in the exam scores between the two tutoring modes. While the regular students achieved 70.04, students enrolled in intensive groups only scored $62.43(\mathrm{p}=0.034)$. there were no significant differences in success rates and in the final course grades.

- Please note that we did not find that all regular groups consistently scored better than the intensive ones, although this was the case in the earlier years. But in later years, more students in general (not only stronger students) tended to register for the regular mode. This may be explained by the fact that registering for either mode entitles students to watch the recorded Zoom group, (an intensive mode), without paying extra

\section{Tutors}

When we evaluated the groups according to specific tutors, we found no significant differences. Sometimes we found one group to be better or worse. But we found that identity of the tutor, day of the week, time, etc. made no difference. We occasionally noted that a group contained several students who were taking the course for the second time; or that had a background in math (studied at the OUI), but no consistent patterns were found.

\section{Discussion and Conclusions}

In this paper we evaluated student success in CS1 courses which included tutoring in the TelAviv study centre groups. We chose to focus on this particular site because of the variety of groups offered. Different groups meet each day of the week, allowing students to choose the group that is most convenient to them. This leads to heterogenic groups that are usually at the same level. We occasionally found one group that was better or worse than the others in a particular semester, but we found no correlation between the success of a particular group with a specific tutor, day of the week, or any other factor. We were glad to find no significant differences between the groups, which shows that the teaching and the learning process of our CS1 course is consistent all over the country.

In the following paragraphs we will explain the factors leading to this result, and how we manage the course in order to achieve this uniform teaching process.

- All OUI students enrolled in a particular course receive identical mandatory course materials at the beginning of each semester, as well as supplementary study materials found on the course website. The face-to-face meetings with tutors are designed to summarize and reinforce the information taught during the course. Although it is very helpful to attend these sessions, no extra topics or skills are taught.

- At the beginning of each semester, students receive a timetable which details the syllabus, including which unit will be taught each week, and which assignments must 
be submitted. As a result, the course progression is unified at all study groups all over the country.

- Before the start of each semester, a tutors meeting is held, in which we gather to discuss pedagogic issues. We share insights about the teaching process for this particular course, and discuss student misconceptions relating to the course which are encountered during tutoring sessions or in assignments, as well as solutions to the issues raised. The tutors share their thoughts about how to teach difficult topics and provide examples they use to demonstrate these issues. They collaborate to design good presentations which can be helpful to all the tutors.

- During the semester, the tutors and the course coordinator keep in touch by email or in a special forum, to help each other solve problems which may arise that are connected to the teaching process.

- Study centre teams are made up of mainly veteran tutors. Turnover is quite low, and most tutors are experts who remain in their positions for several years. Occasionally tutors leave and/or others join.

- In order to make the assignment checking process as consistent as possible, we use this system: Each pair of tutors is given one exercise out of the eight assigned and are expected to prepare a guide detailing how to score the solution, how many points to reduce for each common error etc. The checking process includes two parts: (a) machine checking, which checks the correctness of the solution, and (b) human checking where the tutor reads the code and examines the programming style, the efficiency of the solutions etc. The guide prepared by the two tutors deals with these subjects as well.

- Different forums are provided for students to ask questions about each exercise, and the two tutors are responsible for answering the questions in the forum, so the feedback is uniform for all students.

- For final exams, the course coordinator, assisted by one or two tutors, checks all the exams of all the students. Prior to commencing the grading process, they meet to discuss the errors commonly expected, and how to grade the solutions. Each tutor grades the same question in all the exams. In this way, we guarantee that the checking process will be uniform.

As mentioned above, this course is not considered a MOOC. Although we have an open admissions policy, the teaching of this course is not exclusively online, and, it is part of studies leading to a BSc in computer science. We hope, however, that our many years of experience managing a course with numerous students and the uniform results we achieve can, through this paper, help others who manage MOOCs courses.

\section{References}

Barr, V. (2018). Different Denominators, Different Results: Reanalyzing CS Degrees by

Gender, Race, and Ethnicity. ACM Inroads, 9(3), 40-47.

BlueJ - http://www.bluej.org 
Computer Science Curricula (2013). The Joint Task Force on Computing Curricula. Association for Computing Machinery (ACM) \& IEEE Computer Society. Final Report. Retrieved from https://china.acm.org/SIGCSE/static/images/CS2013-final-report.pdf

Gal-Ezer, J., Vilner, T., \& Zur, E. (2009). The Professor on Your PC: A Virtual CS1 Course. Proceedings of the $13^{\text {th }}$ annual conference on innovation and technology in computer science education, 191-195.

Insa, D., \& Silva, J. (2015). Semi-Automatic Assessment of Unrestrained Java Code. ITiCSE'15 - Proceedings of the 2015 ACM Conference on Innovation and Technology in Computer Science Education, 39-44.

Ju, A., Mehne, B., Halle, A., \& Fox, A. (2018). In-Class Coding-Based Summative Assessments: Tools, Challenges, and Experience. ITiCSE'18 - Proceedings of the 2018 ACM Conference on Innovation and Technology in Computer Science Education, 75-80.

Lewis, J., \& Loftus, W. (2012). Java Software Solutions ( $7^{\text {th }}$ ed.). Pearson Education.

The Open University of Israel (2018). https://www.openu.ac.il/en/pages/default.aspx

Staubitz, T. et al. (2016). Improving the Peer Experience on MOOC Platforms. L@S '16 Proceedings of the $3^{\text {rd }}$ ACM Conference on Learning @ Scale, 389-398.

Stephenson, B. (2018). An Experience Using On-Computer Programming Questions During Exams. WCCCE - Proceedings of the $23^{\text {rd }}$ Western Canadian Conference on Computing Education, 1-6.

Vihvainen, A., Paksula, M., \& Luukkainen, M. (2011). Extreme Apprenticeship Method in Teaching Programming for Beginners. SIGCSE'11 - Proceedings of the $42^{\text {nd }}$ ACM Technical Symposium on Computer Science Education, 93-98.

Vihavainen, A., Luukkainen, M., \& Kurhila, J. (2013). MOOC as Semester-Long Entrance Exam. SIGITE'13 - Proceedings of the 2013 ACM SIGITE Annual Conference on Information Technology Education, 177-182.

Vilner, T., \& Zur, E. (2006). Once She Makes it, She is There: Gender Differences in Computer Science Study. ACM SIGCSE Bulletin, 38(3), 227-231. 